\title{
Cultural Industry System Innovation and Cultural Industry Development: Based on the Comparison of Beijing, Shanghai and Shenzhen
}

\author{
Shanglin Si, Xuefang Xie* \\ School of Humanities \\ Tongji University \\ Shanghai, P.R. China \\ *Corresponding Author
}

\author{
Qinliang Liu \\ School of Media and Communication \\ Shanghai Jiaotong University \\ Shanghai, P.R. China
}

\begin{abstract}
The actively innovation of cultural industry system brings about the good status of cultural industry's development. In Beijing, Shanghai and Shenzhen, a large number of cultural industry giants are clustering, which is due to the innovation of cultural industry system. As for the proportion of technological innovation policy, Shenzhen $(0.80)$ has the advantage of technological innovation in sum, which is higher than Beijing (0.67) and Shanghai (0.56). The rangeability of government subsidy policy in Shanghai is greater than Beijing and Shenzhen. From the perspective of the proportion of supportive policies of cultural enterprises, Beijing (0.07) had made a lot of policies which more than Shanghai's $(\mathbf{0 . 0 5})$ and Shenzhen's $(0.03)$. Compared with the innovation competence of cultural industry system, Shanghai's innovation competence index (18.02) is higher than Beijing's (16.04) and Shenzhen's (13.77). In view of this, achieving the intimately interaction between cultural industry system innovation and cultural industry development environment will be the key factor for the innovation of cultural industry system in the future.
\end{abstract}

Keywords-Cultural industry, System innovation, Comparison, Scientific and Technological innovation

\section{INTRODUCTION}

The Internet and public innovation are being integrated into the creation, production and marketing of culture (Parmentier \& Mangematin, 2014)[1], which bring the development of cultural industry. The traditional cultural industry is closely integrated with the Internet and mobile Internet, thus the era of "Digital and Internet" is coming, and the cultural industry towards the "micro-market" development (Goyal et al., 2012)[2]. In the field of new patterns of cultural industries, numbers of cultural products are emerging in an endless stream, such as mobile games, Live webcast, VR audio-visual and so on, which speeds up the replacement process of cultural products. At the same time, the problem of cultural industry is endlessly, so that, cultural industry also has a high demand for the innovation of cultural policy and system.

According to research, policies play an important role in promoting the gathering of cultural industries, but too much policy intervention is not conducive to the development of cultural and creative's space (Chou, 2012) [3]. Darchen and

This research was financially supported by the Major projects of National Social Science Fund (Grant No.20ZDA065), the General project of Shanghai philosophy and Social Science Planning Foundation (Grant No.2019CGL100), and sponsored by Shanghai Shuguang Program (Grant NO.19SG20)
Tremblay (2015) had argued that the impact of government policies on the development and aggregation of emerging video game industries is limited [4]. Therefore, this paper takes Beijing, Shanghai and Shenzhen as examples to explore the innovation proposition of cultural industry system. The purpose of this study is to grasp the logical rules between system innovation and cultural industry systematically, and to promote the development of urban cultural ecology environment and cultural industry preferably.

\section{THE CHARACTERISTIC OF CULTURAL INDUSTRIES} SYSTEM INNOVATION IN BEIJING, SHANGHAI AND SHENZHEN

Beijing, Shanghai and Shenzhen developed maturely on cultural industry, a series of policies on cultural industry have been made by numerous cultural administration institutions. Among them, culture industry system includes cultural market approval, broadcast and film management, press and publication management, sports management, tourism management, industrial management, foreign cultural exchange management, management of cultural relics, market supervision, and so on. It also relates to the industries of public culture, film and television, entertainment, Internet culture, animation, exhibition, travel, publishing, printing copy, art product, and so on. As to the administration institutions, it includes People's government, propaganda department, finance bureau, industrial and commercial administration, cultural bureau ${ }^{1}$.

Compared to the total amount of cultural industry's policies from 2006 to $2015^{2}$, Shanghai ranks first (117), and then Beijing (94) and Shenzhen (74). For the number of the cultural industry policies issued in 2006-2015, it had different characteristics among Beijing, Shanghai and Shenzhen.

First of all, the trend of cultural policies issued each year in Shanghai like U - shaped, of which year 2006, 2014, 2015, cultural industry policies were issued most centrally with 12 , 25,34 respectively. There is a big gap between different years, 2007 year issued 2 policies, only be $1 / 17$ of year 2015. The dynamic of Shanghai's cultural industry system innovation is influenced by the national macro-policy. On the one hand, the

\footnotetext{
${ }^{1}$ Due to the different functions of the administrative agencies, the name of the organization has some differences.

${ }^{2}$ Source: According to the official website of the various government departments, the official website of the data statistics, specific cultural policy information see Appendix.
} 
"National Eleventh Five-Year Cultural Development Plan" was promulgated in 2006, then each region began to strengthen the management and guidance of the cultural market and cultural sites. In 2006, the cultural industry policy of Shanghai were issued mainly on the cultural service agencies and cultural products production management. On the other hand, from 2014 to 2015 , the cultural industry policy system was improved by the deepen reform of China's political system and improvement of Cultural Industry innovation system. In a good background, Shanghai put forward the goal of establishing a global center of science and technology innovation. A series of cultural industry policies which involved in technology, finance, culture, talent, enterprises, industrial parks, universities, research institutes have been formulated by Shanghai Government, Shanghai Municipal Science and Technology Commission, which improves the scientific and technological innovation policy system perfectly and also is good ready for the establishment of global science and technology innovation center, such as "a number of supporting policies to further increase financial support to accelerate the construction of a globally influential science and technology innovation center".

Secondly, the innovation of cultural industry system in Beijing is more stably, besides, 2011 is the peak period of innovation of Beijing's cultural industry system, which matches the development characteristics of Beijing's cultural industry. At the same time, the peak period of cultural industry system's innovation were 2008 and 2012 in Shenzhen. The reason is that "Shenzhen's cultural industry development planning outline (2007-2020)" was released in 2008 which based on the current situation of the development of cultural industry in Shenzhen, which improved the relevant policies system's innovation and promoted the development of cultural industries perfectly. In 2012, it was a crucial year for the reform and development of Shenzhen's cultural industries. And in May 2012, the ministry of science and technology, the central propaganda department, the ministry of culture jointly issued the "national culture and science and technology innovation project outline". Shenzhen responded to the national policy actively and promoted the development of technology and culture, setting up perfect policy on research, development investment and scientific research personnel.

\section{COMPARISON OF CULTURAL INDUSTRY SYSTEMS} INNOVATION AMONG BEIJING, SHANGHAI AND SHENZHEN

\section{A. Comparison of Scientific and Technological Innovation System in Cultural Industry}

Cultural industry system covers a wide range of content. The science and technology innovation system of cultural industry involves the industrial macro environment, taxation system, cultural enterprises and other aspects. In the last decade, the number of science and technology policies of cultural industry in Beijing, Shanghai and Shenzhen is almost the same, respectively, 63, 65, 59. Scientific and technological innovation accounts for the proportion of cultural industry system differently in different regions, Beijing(0.56) compared to Shanghai(0.56) and Shenzhen(0.80), all the three cities' have gone beyond more than one-half of the total cultural industry system, it means that Beijing, Shanghai, Shenzhen's municipal governments have recognized the importance of cultural and technological innovation on the development of the entire cultural industry, it also shows that Beijing, Shanghai, Shenzhen have gone beyond other cities in the term of cultural and technology innovation. Among them, the proportion of technological innovation in Shenzhen's cultural industry as high as 0.8 , indicating that Shenzhen has been committed to the using of science and technology innovation system to promote the development of the entire cultural industry. Although less of leading cultural company, but it has high technological innovation capability. Shanghai, although owns 112 of cultural industry policies and ranks at the first place, but the capacity index of scientific and technological innovation system is only 0.56 . The lag of institutional innovation has brought the slowly development of science and technology innovation of Shanghai's culture industry.

TABLE I. Number AND PROPORTION OF CULTURAL AND TECHNOLOGICAL Policies 2006-2015

\begin{tabular}{|c|c|c|c|c|c|c|}
\hline \multirow{2}{*}{$\begin{array}{l}\text { number and } \\
\text { proportion }\end{array}$} & \multicolumn{2}{|c|}{ Beijing } & \multicolumn{2}{|c|}{ Shanghai } & \multicolumn{2}{|c|}{ Shenzhen } \\
\hline & Number & $\begin{array}{l}\text { Proportion } \\
\text { index }\end{array}$ & Number & $\begin{array}{l}\text { Proportion } \\
\text { index }\end{array}$ & Number & $\begin{array}{c}\text { Proportion } \\
\text { index }\end{array}$ \\
\hline 2006 & 8 & 0.57 & 0 & 0 & 2 & 1 \\
\hline 2007 & 8 & 0.89 & 0 & 0 & 0 & 0 \\
\hline 2008 & 3 & 0.6 & 1 & 0.125 & 19 & 0.90 \\
\hline 2009 & 6 & 0.86 & 2 & 0.4 & 2 & 0.5 \\
\hline 2010 & 4 & 0.57 & 3 & 0.75 & 5 & 1 \\
\hline 2011 & 11 & 0.85 & 10 & 0.71 & 4 & 1 \\
\hline 2012 & 5 & 0.5 & 6 & 1 & 12 & 0.63 \\
\hline 2013 & 6 & 0.67 & 6 & 0.86 & 5 & 0.625 \\
\hline 2014 & 7 & 0.7 & 13 & 0.52 & 4 & 1 \\
\hline 2015 & 5 & 0.5 & 25 & 0.74 & 6 & 0.86 \\
\hline sum & 63 & 0.67 & 65 & 0.56 & 59 & 0.80 \\
\hline
\end{tabular}

The rend of cultural industry's technology innovation as same as the trend of cultural industry system's innovation development, and the peak of policies number at the same year. Among them, the science and technology policies' evolution of 
cultural industry in Beijing is obvious. In 2011, Beijing issued a total of 11 cultural and technological innovation policies, that mainly influenced by the government's policies like the "development plan of cultural creative industry during the 12th five-year plan period", "the plan for the development of science and technology in Beijing during the 12th five-year plan period". The implementation of macro-level planning needs the specific guidance and measures as the supplement, so that, 2011 had been the special year for the cultural industry science and technology innovation development in Beijing.

\section{B. Comparison of the Effect of Government Subsidy System in Cultural Industry}

Given the availability of data, evaluating the effect of the government subsidy system on cultural industries is mainly based on the data disclosed by listed companies. From 2006 to 2015 , the total amount of allowance from government to listed companies going up in Beijing, Shanghai and Shenzhen. Actually, the proportion of government's subsidies externally reflect the influence of government subsidies on the cultural enterprises. From 2006-2015, the proportion of Beijing government's subsidies on listed companies of cultural industries, as a whole, has been hovering between 0.009-0.030. The proportion of Shanghai's governmental subsidies on listed companies of cultural industry varied greatly, specially in 2013 , the proportion index is 0.172 , which benefited from the introduction of three governmental subsidies policies in 2013, respectively as the "Shanghai Science and Technology SME Technology Innovation Fund Management Measures", "Shanghai Science and Technology Award Regulations Implementation Rules" and so on. From 2006 to 2014, the proportion of Shenzhen government's subsidies on listed companies of cultural industry had changed little, but in 2015 the proportion of government's subsidies increased rapidly, although the number of cultural industry listed companies in Shenzhen is less, but the sum of government's subsidies is high on cultural industry. In general, the biggest beneficiaries of cultural industry subsidy system were the cultural enterprises with a certain technological innovation capacity.

\section{Comparison of Supporting System of Cultural Enterprises}

According to the statistical data, from 2006 to 2015, seven policies relevant to cultural enterprises in Beijing that accounting for the proportion of cultural system innovation is 0.074. Shanghai had implemented six policies related to cultural enterprises, accounting for the proportion of total system is 0.051 . Shenzhen had two policies for cultural enterprises, accounting for the proportion of the total cultural industry system is 0.025 . When the government promulgates the cultural industry policies, the government usually focuses on the system innovation at the macro-level and has little attention to the meso- level and the micro- level, which leads to the less concentration on the cultural industry system and indirectly reduces the effect of the system. Therefore, the goal of establishing the targeted, operable system is not only for Beijing, Shanghai, Shenzhen but also for other areas. Specifically, policies for the cultural enterprise support system, apart from the terms of fiscal, tax and technological innovation, furthermore, policies should play a role on the protection of copyright, speed up the improvement of digital copyright and network copyright protection system [5].

\section{Comparison of Comprehensive Index of Cultural Industry System Innovation}

The innovation of cultural industry system is not determined by the single factor, but is the result of the synthesis of multiple factors, At the same time, the relevant data of cultural industry system was collected by author from the science and technology commission, cultural organization department of the people's government and other official website statistics of Beijing, Shanghai and Shenzhen. By the calculation, the each weight index of cultural industry system innovation's capability is as follows (Table II):

TABLE II. CULTURAL INDUSTRY SySTEM INNOVATION STRENGTH INDEX WEIGHT COEFFICIENT

\begin{tabular}{|c|c|c|}
\hline Cultural policy & Total number of cultural policies & 0.081 \\
\hline $\begin{array}{c}\text { Cultural and } \\
\text { technological } \\
\text { policy }\end{array}$ & $\begin{array}{c}\text { Number of cultural and technological } \\
\text { policies }\end{array}$ & 0.122 \\
\cline { 2 - 3 } & $\begin{array}{c}\text { The proportion of cultural science } \\
\text { and technology policy }\end{array}$ & 0.629 \\
\hline $\begin{array}{c}\text { Cultural } \\
\text { enterprise } \\
\text { policy }\end{array}$ & $\begin{array}{c}\text { Number of cultural enterprise } \\
\text { policies }\end{array}$ & 0.047 \\
\cline { 2 - 3 } & $\begin{array}{c}\text { The proportion of Cultural enterprise } \\
\text { policy }\end{array}$ & 0.141 \\
\hline
\end{tabular}

The system innovation intensity of cultural industry among in Beijing, Shanghai and Shenzhen is different (Table III). The innovation intensity of Shanghai's cultural industry system is the highest (18.02), indicating that cultural industry system innovation is more actively than others. Behind Shanghai, Beijing in the second is 16.04, and then is Shenzhen (13.77). But it needs to be pointed out that there is no one-to-one relationship between the active innovation of the system and the good ecological environment of the cultural industry. Compared to Beijing and Shanghai, Shenzhen has the weakly institutional innovation, but the innovation environment and talent environment are better than Beijing and Shanghai. Therefore, how to achieve the interaction between system innovation and development environment of cultural industry is the main mission.

TABLE III. COMPREHENSIVE OF INNOVATION STRENGTH OF THE CULTURAL INDUSTRY SYSTEM

\begin{tabular}{|c|c|c|c|}
\hline Comprehensive index & Beijing & Shanghai & Shenzhen \\
\hline $\begin{array}{c}\text { Total number } \\
\text { of cultural policy }\end{array}$ & 94 & 117 & 74 \\
\hline $\begin{array}{c}\text { Number of cultural and } \\
\text { technological policies }\end{array}$ & 63 & 65 & 59 \\
\hline $\begin{array}{c}\text { Proportion of cultural } \\
\text { and technological } \\
\text { policies }\end{array}$ & 0.670 & 0.556 & 0.797 \\
\hline $\begin{array}{c}\text { Number of cultural } \\
\text { enterprises policy }\end{array}$ & 7 & 6 & 2 \\
\hline $\begin{array}{c}\text { Proportion of cultural } \\
\text { enterprises policy }\end{array}$ & 0.075 & 0.051 & 0.027 \\
\hline comprehensive index & 16.040 & 18.022 & 13.772 \\
\hline
\end{tabular}




\section{CONCLUSION}

The influence of system innovation on the development of cultural industry is becoming more and more obvious. In the era of "Internet +", emerging cultural industries emerge in endlessly, and the creative process of cultural industry is being continuously reshaped by digital technology [6], and demands for the innovation of cultural industry system are more and more higher. On the content, the innovation of cultural industry system should focus on the construction of cultural industry platform, the introduction of cultural innovation talents, technological innovation of cultural industry to develop new type of cultural industries.

On the path, we should deal with the logical relationship between functional policy and selective policy of culture industry. A number of measures should be taken to adapt to the dynamic innovation of cultural industry, provide more efficient system support for cultural enterprises and incentive the collaborative innovation of culture industry. Particularly Also, the Internet cultural enterprises should improve their capacities for technological innovation, content creation, and managerial innovation throughout their entire operations to create competitive advantages (Palacios-Marqués et al. 2017 [7]; Xie et al. 2019[8]).

\section{REFERENCES}

[1] G. Parmentier and V. Mangematin, "Orchestrating innovation with user communities in the creative industries", Technological Forecasting and Social Change, vol. 83, 2014, pp. 40-53.

[2] M. Goyal, M. Q. Hancock and H. Hatami, "Selling into Micro-markets, Harvard Business Review”, vol. 7,2012, pp. 78-86.

[3] S. L. Chou, Creative Space, "Cultural Industry Clusters, and Participation of the State in Beijing", Eurasian Geography and Economics, vol. 53, 2012, pp. 197-215.

[4] S. Darchen and D. G. Tremblay, "Policies for Creative Clusters:A Comparison between the Video Game Industries in Melbourne and Montreal", European Planning Studies, vol. 23,2015,pp. 311-331.

[5] L. Edwards, B. Klein, D. Lee, G. Moss, and F. Philip, "Discourse, justification and critique: towards a legitimate digital copyright regime?" International Journal of Cultural Policy, vol. 21, 2015, pp. 60-77.

[6] P. L. Le, D. Masse, and T. Paris, "Technological change at the heart of the creative process: insights from the video game industry", International Journal of Arts Management, vol. 15, 2013, pp. 45-59.

[7] Palacios-Marqués, D., Roig-Dobón, S., \& Comeig, I. "Background factors to innovation performance: Results of an empirical study using fsQCA methodology”, Quality\&Quantity, 51(5),2017, PP.1939-1953.

[8] X.F. Xie, X.M. Xie,"Identifying the factors determining the entrepreneurial ecosystem of Internet cultural industries in emerging economies",International Entrepreneurship and Management Journal,(4),2019,PP.503-522. 